\title{
Rectifier Design Challenges for RF Wireless Power Transfer and Energy Harvesting Systems
}

\author{
Ana COLLADO ${ }^{1}$, Spyridon-Nektarios DASKALAKIS ${ }^{1}$, Kyriaki NIOTAKI ${ }^{2}$, \\ Ricard MARTINEZ ${ }^{3}$, Ferran BOLOS ${ }^{3}$, Apostolos GEORGIADIS ${ }^{1}$ \\ ${ }^{1}$ School of Engineering and Physical Sciences, Heriot-Watt University, Edinburgh, United Kingdom \\ ${ }^{2}$ Bentel Ltd., Guinness Enterprise Centre, Taylor's Lane, Dublin 8, Ireland \\ ${ }^{3}$ Polytechnic University of Catalonia, Barcelona, Spain
}

a.collado_garrido@hw.ac.uk, a.georgiadis@hw.ac.uk,sd70@hw.ac.uk,nkiriaki@gmail.com, ferranbolos9@gmail.com

Submitted May 3, 2017 / Accepted May 3, 2017

\begin{abstract}
The design of wireless power transfer (WPT) and energy harvesting (EH) solutions poses different challenges towards achieving maximum RF-DC conversion efficiency in these systems. This paper covers several selected challenges when developing WPT and electromagnetic EH solutions, such as the design of multiband and broadband rectifiers, the minimization of the effect that load and input power variations may have on the system performance and finally the most optimum power combining mechanisms that can be used when dealing with multielement rectifiers.
\end{abstract}

\section{Keywords}

Wireless power transfer, energy harvesting, rectifier, rectenna, Schottky diode, multiband rectifier, broadband rectifier, wideband rectifier

\section{Introduction}

Wireless power transfer (WPT) and energy harvesting (EH) solutions are receiving a lot of attention towards providing autonomy to a wide variety of sensors and devices. These self-sustainability properties allow implementing concepts such as the Internet of Things (IoT), smart cities and smart buildings to name a few. However both WPT and EH solution synthesis pose several design challenges that need to be addressed towards achieving an optimum performance.

In the case of electromagnetic $\mathrm{EH}$ the amount of available power from a selected RF energy source may be variable and unpredictable. This is why several solutions where it is possible to harvest from more than one frequency band have been proposed in the literature [1-11]. These solutions are based on the use of multiband rectifiers or in the combination of the DC outputs of several single band rectifiers. In [3], [5] dual band electromagnetic energy harvesting is proposed where the energy is collected from two different RF frequency bands, while in [1, 2, 4] triple band $\mathrm{EH}$ is considered. Some other works focus on broadband electromagnetic EH [7-11] where the energy is collected from a selected range of continuous frequencies.

A common challenge for both WPT and EH is the fact that due to the nonlinear nature of the rectifying devices the performance of rectifier circuits in terms of RFDC conversion efficiency get easily affected by variations in the input power level and also in the output load. In order to minimize the effect these variations have on the overall performance some authors have considered using several rectifying branches [11] each one optimized to operate at a different input power level. Other works combine the use of a JFET transistor and a Schottky diode to synthesize a rectifier that can operate for both large and small input powers levels [13]. Some other works propose the use of resistance compression networks (RCN) in order to minimize the variations in power and load that reach the rectifying element $[14,15]$.

Other challenge in designing rectifier circuits for WPT and EH is the use of arrays of either antennas or rectenna elements. The selection of either one of the options depends on the amount of power that is being received and the rectifying element selected. One challenge in designing these arrays is the DC power combining mechanism of the rectifier outputs. Some works have covered this topic [16-18] showing results on how the optimum load varies depending of the type of DC power combination performed, series, parallel or combined.

In this paper, some of the previously mentioned solutions towards addressing the challenges in WPT and EH solutions are covered in more detail. In Sec. 2, a state of the art review of existing multiband and broadband designs of rectifiers is presented and an example of a broadband rectifier is explained. In Sec. 3, the design of a rectifier using RCN is presented for minimizing the effect that load and input power variations have on the rectifier performance. Section 4 focuses on the design of a rectenna array and how the DC outputs can be combined towards maximizing the RF-DC conversion efficiency and how the 
optimum load is different depending on the type of combination performed (series/parallel) as well as on the angle of arrival of the RF incoming signal.

\section{Multi-band/Broadband Rectifiers}

As previously mentioned, a key goal in rectenna and rectifier design is to maximize the RF-DC conversion efficiency. One alternative is to perform a multiband or broadband design for the rectifier circuit. This is important if one is considering to perform electromagnetic EH from different broadcast transmissions that operate at different frequencies.

Table 1 shows several state of the art results regarding multiband rectifier designs [1-5] showing efficiencies in the order of $15 \%$ for $-20 \mathrm{dBm}$ input power for dual band rectifiers [5] where a single diode is used and efficiencies in above $25 \%$ for triple band rectifiers with $-15 \mathrm{dBm}$ input power where a dedicated branch for each frequency is considered [2].

Table 2 shows several state of the art results regarding broadband rectifier design [7-11]. The design in [10] is capable of harvesting in the $2-18 \mathrm{GHz}$ frequency band with efficiencies of $20 \%$ for $15 \mathrm{dBm}$ input power at $3 \mathrm{GHz}$ using a single diode rectifier in a 64 element array configuration. The design in [8] uses a 5-stage charge pump circuit to obtain efficiencies $>30 \%$ for $18 \mathrm{dBm}$ input power.

The challenge in designing ultra-wideband rectifiers is of fundamental nature. A rectifier circuit is a capacitive load, with an equivalent circuit which consists of a shunt resistor in parallel with a shunt capacitor. The equivalent circuit elements are nonlinear in nature and depend on the input power, output load as well as the circuit topology of the rectifier [19]. The minimum reflection coefficient that can be achieved using a lossless network to obtain broadband impedance matching over a desired frequency band is bound by the theoretical limit obtained in the work of Bode and Fano [20]. In [19], a wideband rectifier with an octave bandwidth is proposed where a matching network based on a non-uniform transmission line is used. A photo of the rectifier is shown in Fig. 1 and the results in terms of RFDC conversion efficiency versus frequency are depicted in Fig. 2. A measured efficiency of more than $60 \%$ was obtained for $10 \mathrm{dBm}$ input power in the $470 \mathrm{MHz}$ to $860 \mathrm{MHz}$ frequency band.

\begin{tabular}{|c|c|c|c|c|c|c|c|}
\hline Reference & $\begin{array}{c}\text { Frequency of } \\
\text { operation } \\
\text { (MHz) }\end{array}$ & Topology & Pav (dBm) & Efficiency (\%) & RL (Ohm) & Vdc (mV) & $\begin{array}{c}\text { No. } \\
\text { elements }\end{array}$ \\
\hline$[1]$ & $\begin{array}{c}900,1800, \\
2400\end{array}$ & $\begin{array}{c}\text { Full wave } \\
\text { rectifier }\end{array}$ & 1.76 & $\begin{array}{c}60 \text { at } 900 \mathrm{MHz} \\
47 \text { at } 1760 \mathrm{MHz} \\
33.5 \text { at } 2.45 \mathrm{GHz}\end{array}$ & 6300 & $\begin{array}{c}2381 \text { at } 900 \mathrm{MHz} \\
2100 \text { at } 1760 \mathrm{MHz} \\
1774.8 \text { at } 2.45 \mathrm{GHz}\end{array}$ & 1 \\
\hline$[2]$ & $\begin{array}{c}900,1800, \\
2400\end{array}$ & $\begin{array}{c}\text { Three charge } \\
\text { pump } \\
\text { branches }\end{array}$ & -15 & $\begin{array}{c}45 \text { at } 900 \mathrm{MHz} \\
46 \text { at } 1800 \mathrm{MHz} \\
25 \text { at } 2.45 \mathrm{GHz}\end{array}$ & 50000 & $\begin{array}{c}0.82 \text { at } 900 \mathrm{MHz} \\
0.85 \text { at } 1800 \mathrm{MHz} \\
0.62 \text { at } 2.45 \mathrm{GHz}\end{array}$ & 1 \\
\hline$[3]$ & 915,2450 & $\begin{array}{c}\text { Single diode } \\
\text { rectifier }\end{array}$ & $\begin{array}{c}-11 \\
\text { at } 915 \mathrm{MHz} \\
-13.5\end{array}$ & $\begin{array}{c}4.7 \text { at } 915 \mathrm{MHz} \\
56.2 \text { at } 2.45 \mathrm{GHz}\end{array}$ & 2200 & $\begin{array}{c}200 \text { at } 915 \mathrm{MHz} \\
\text { at } 2.45 \mathrm{GHz}\end{array}$ & $\begin{array}{c}313.5 \mathrm{at} 2.45 \mathrm{GHz} \\
1\end{array}$ \\
\hline$[4]$ & 900,1800, & $\begin{array}{c}\text { Single series } \\
\text { diode }\end{array}$ & 27 & $\begin{array}{c}\sim 50 \text { at } 900 \mathrm{MHz}, \\
1800 \mathrm{MHz}, \\
2.4 \mathrm{GHz}\end{array}$ & 50 & $\begin{array}{c}\sim 250 \mathrm{mV} \text { at } 900 \mathrm{MHz}, \\
1800 \mathrm{MHz}, 2.4 \mathrm{GHz}\end{array}$ & 1 \\
\hline$[5]$ & 850,1850 & $\begin{array}{c}\text { Single series } \\
\text { diode }\end{array}$ & -20 & $\begin{array}{c}15 \text { at } 850 \mathrm{MHz} \\
15 \text { at } 1850 \mathrm{MHz}\end{array}$ & 2200 & $\begin{array}{c}57.4 \mathrm{at} 850 \mathrm{MHz} \\
57.4 \mathrm{at} 1850 \mathrm{MHz}\end{array}$ & 1 \\
\hline$[5]$ & 850,2450 & $\begin{array}{c}\text { Single series } \\
\text { diode }\end{array}$ & -20 & $\begin{array}{c}18 \text { at } 850 \mathrm{MHz} \\
10 \text { at } 2.45 \mathrm{GHz}\end{array}$ & 2200 & $\begin{array}{c}46.9 \mathrm{at} 850 \mathrm{MHz} \\
62.9 \mathrm{at} 2.45 \mathrm{GHz}\end{array}$ & 1 \\
\hline$[6]$ & 791,1570, & $\begin{array}{c}\text { Single series } \\
\text { diode }\end{array}$ & -10 & $\begin{array}{c}\sim 40 \text { at } 791 \mathrm{MHz}, \\
1570 \mathrm{MHz}, \\
2340 \mathrm{MHz}\end{array}$ & 1470 & $\begin{array}{c}\sim 242 \mathrm{at} 791 \mathrm{MHz}, \\
1570 \mathrm{MHz}, 2340 \mathrm{MHz}\end{array}$ & 1 \\
\hline
\end{tabular}

Tab. 1. Comparison of different multiband rectifier design.

\begin{tabular}{|c|c|c|c|c|c|c|c|}
\hline Reference & $\begin{array}{c}\text { Frequency of } \\
\text { operation }\end{array}$ & Topology & Pav (dBm) & Efficiency (\%) & RL (Ohm) & Vdc (mV) & $\begin{array}{c}\text { No. } \\
\text { elements }\end{array}$ \\
\hline$[7]$ & {$[2.41-2.47] \mathrm{GHz}$} & $\begin{array}{c}\text { Single shunt } \\
\text { diode }\end{array}$ & -20 & 24.3 & 1800 & 70 & 1 \\
\hline$[8]$ & $\sim[800-1000] \mathrm{MHz}$ & $\begin{array}{c}5 \text { stage charge } \\
\text { pump circuit }\end{array}$ & 18 & 31.8 & 200 & 6000 & 1 \\
\hline$[9]$ & {$[600-1150] \mathrm{MHz}$} & $\begin{array}{c}\text { Class F-1 } \\
\text { amplifier } \\
\text { based }\end{array}$ & 40 & $>60$ & 34 & 521.5 & 1 \\
\hline$[10]$ & {$[2-18] \mathrm{GHz}$} & Single diode & $\begin{array}{c}{[-17 \ldots+15]} \\
\text { at } 3 \mathrm{GHz}\end{array}$ & $\begin{array}{c}{[0.1-20]} \\
\text { at } 3 \mathrm{GHz}\end{array}$ & 100 & $\begin{array}{c}{[2.5-790]} \\
\text { at } 3 \mathrm{GHz}\end{array}$ & 64 \\
\hline$[11,19]$ & {$[470-860] \mathrm{MHz}$} & Single diode & 10 & $>60$ & & & 1 \\
\hline
\end{tabular}

Tab. 2. Comparison of different broadband rectifier design. 


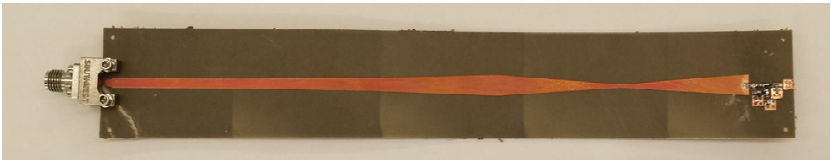

Fig. 1. Broadband rectifier operating in the $470-860 \mathrm{MHz}$ frequency band.

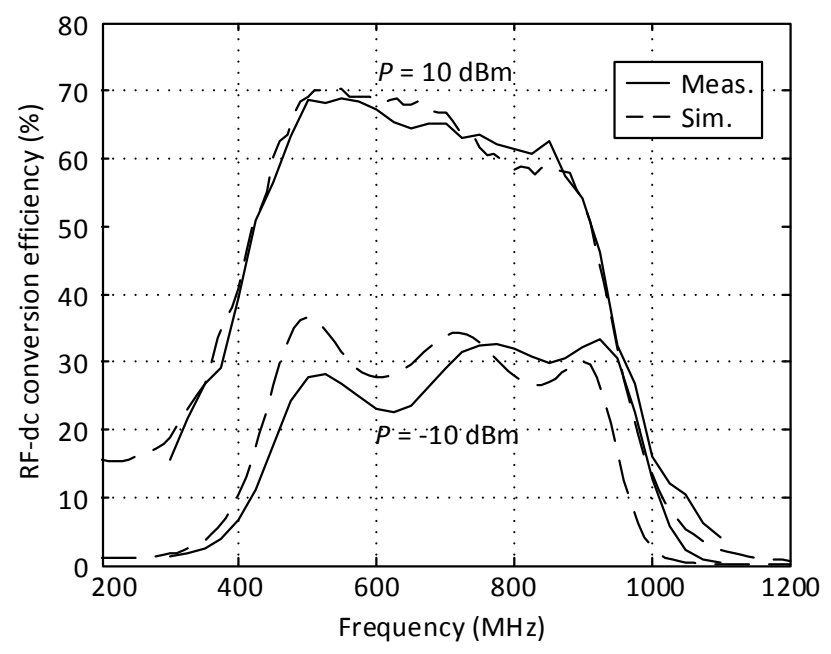

Fig. 2. RF-DC conversion efficiency versus frequency for the broadband rectifier of Fig. 1 [19].

\section{Rectenna Arrays and DC Power Combining}

It is well known that there exists an optimum load in a rectifier circuit that maximizes its RF-DC conversion efficiency. This optimum load depends on several parameters, namely the available input power, the signal characteristics as well as rectifier circuit topology [21]. It is possible to set the value of the optimum load by using a rectenna array and connecting the various rectifier DC outputs in series or parallel combinations [16-18]. When designing rectenna arrays there is a trade-off between designing antenna subarrays where each sub-array feeds one rectifier or creating a full rectenna array where one antenna feeds one rectifier. The first one first combines the RF power and the $\mathrm{DC}$ outputs and the second one combines all the DC rectifier outputs. The target is always to maximize the RF-DC conversion efficiency.

Figure 3 shows a $2 \times 2$ rectenna array designed to operate at $2.4 \mathrm{GHz}$. The rectenna elements consisted of a shorted circular slot antenna, an impedance matching network and a series Shottky diode rectifier.

The value of the optimum load resistance was investigated for different topologies for the combination of the rectifiers DC outputs but also for different angles of incidence of the incoming continuous wave $(\mathrm{CW})$ signal. The results are shown in Fig. 4 where it can be seen that agreeing with other existing studies in the literature [16-18], the optimum load is increased when a series rectifier connection is formed, whereas it is reduced when a parallel connection is used.

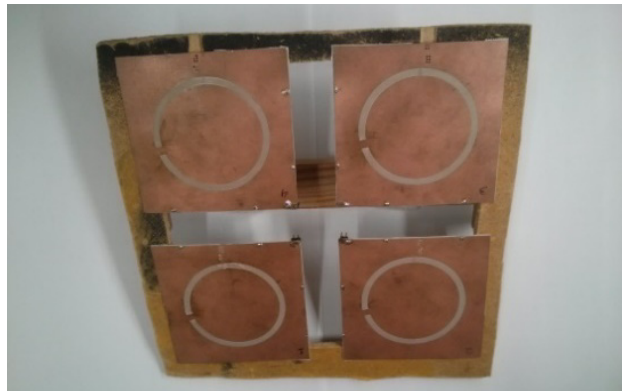

(a)

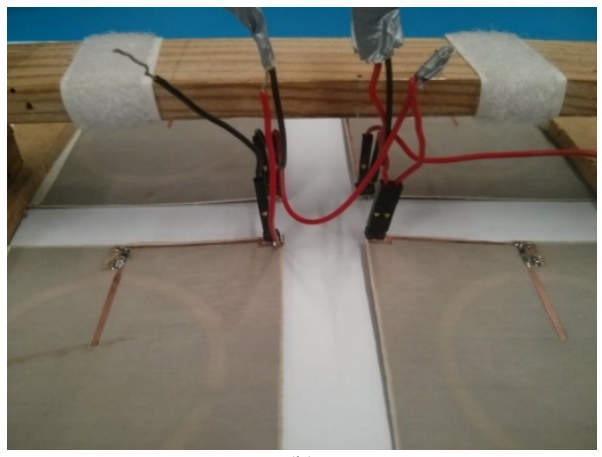

(b)

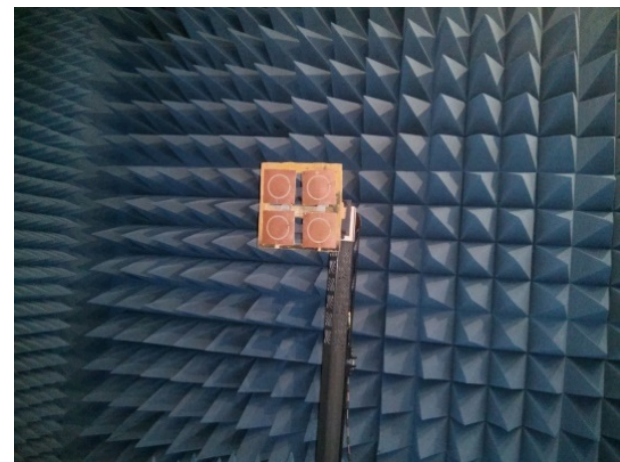

(c)

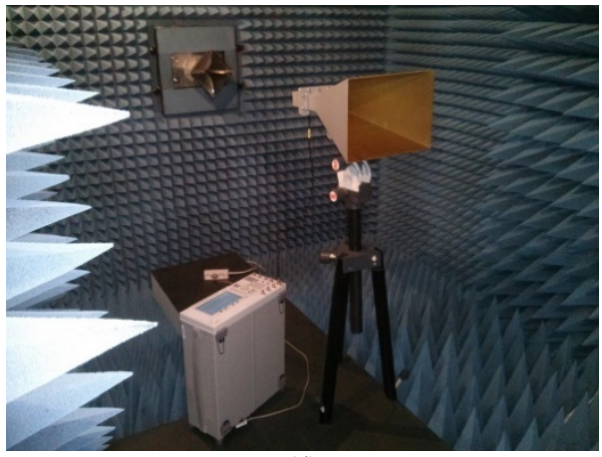

(d)

Fig. 3. Rectenna array: a) fabricated prototype antenna side, b) fabricated prototype rectifier side, c) receive rectenna array setup in an anechoic chamber, d) transmitter setup exciting the rectenna array.

The study performed versus the direction of the incoming wave shows that the optimum load is also dependent on this direction due to the existing mutual coupling among the antenna elements. For the rectenna array in Fig. 3 the optimum load increases as the angle of incidence deviates from broadside. 


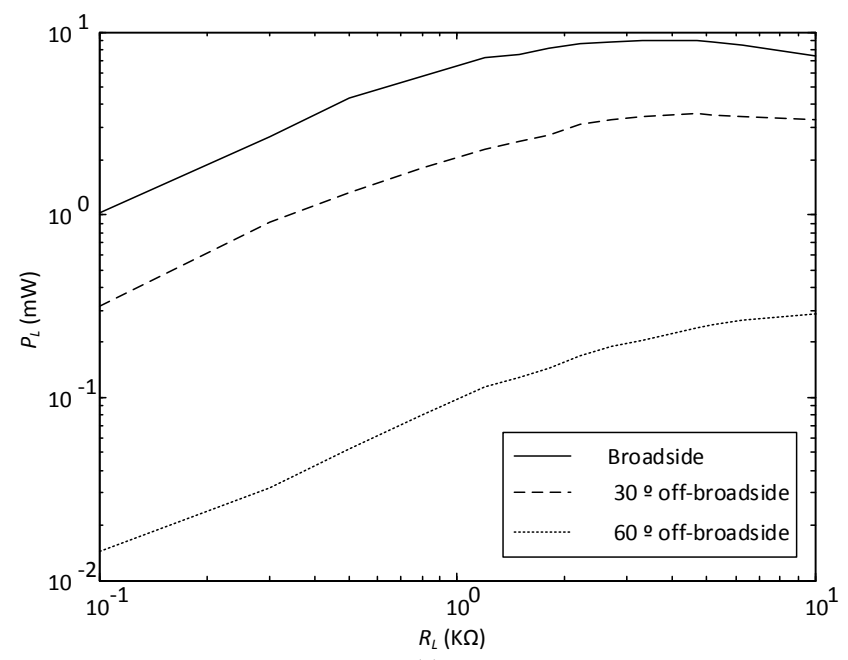

(a)

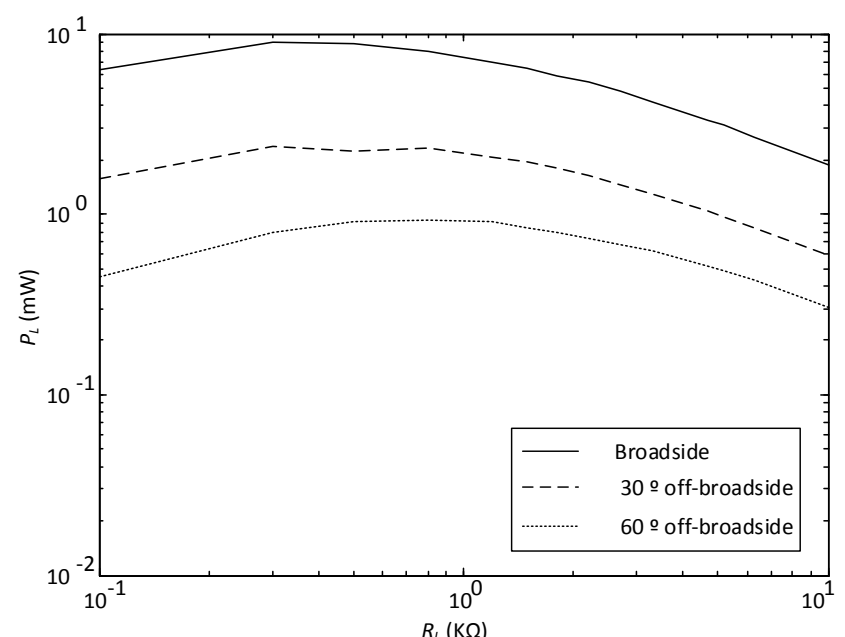

(b)

Fig. 4. Rectenna array output DC power versus the output load resistance for different incoming wave angle of incidence relative to broadside: (a) series connection of the rectifier outputs, b) parallel connection of the rectifier outputs.

\section{Load/Input Power Variations in Rectifier Circuits}

The RF-DC conversion efficiency in a rectifier circuit may be affected by variations in the input power level and in the output load resistance. This means when designing a rectifier it is of key importance to minimize the effect these variations will have on the rectifier performance by selecting a rectifier architecture that is insensitive to power and load changes. In [22] a method to improve the dynamic range in rectifier circuits was proposed. This method makes use of two branches, such as in a Doherty topology used in power amplifier design, to achieve efficiencies above $50 \%$ in an input power level range from $-7 \mathrm{dBm}$ to $16 \mathrm{dBm}$. In [14] a resistance compression network (RCN) is used to keep a high RF-DC conversion efficiency versus a large range of output load values. The RCN is formed by two parallel branches which have 2 identical variable loads

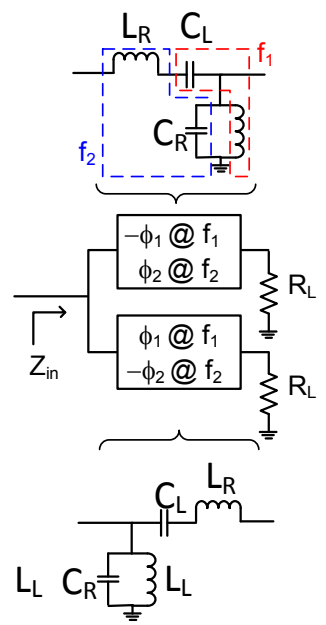

Fig. 5. Dual band RCN used in the rectifier design in [15]. Parallel connection of two branches which include identical copies of the variable load and reactive networks introducing a properly designed and opposite phase at the two desired operation frequencies.

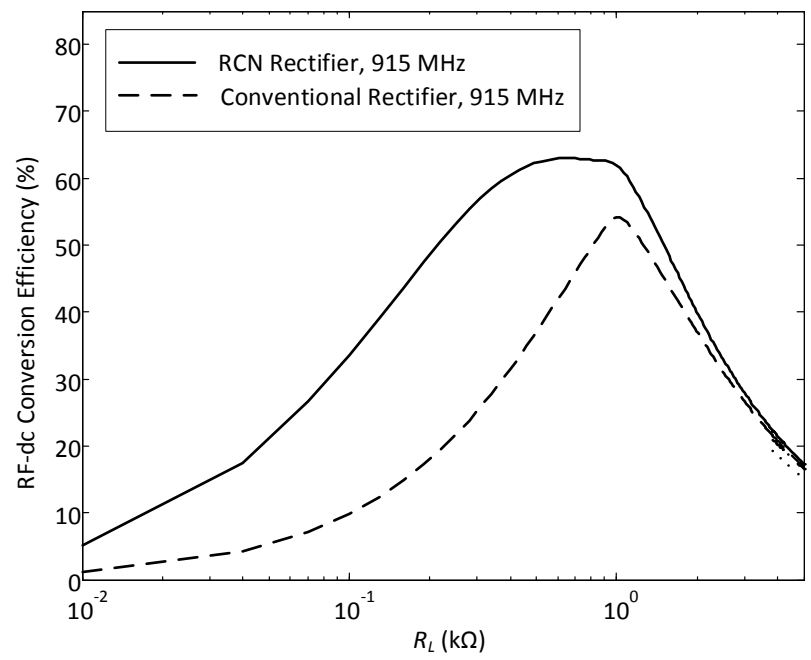

(a)

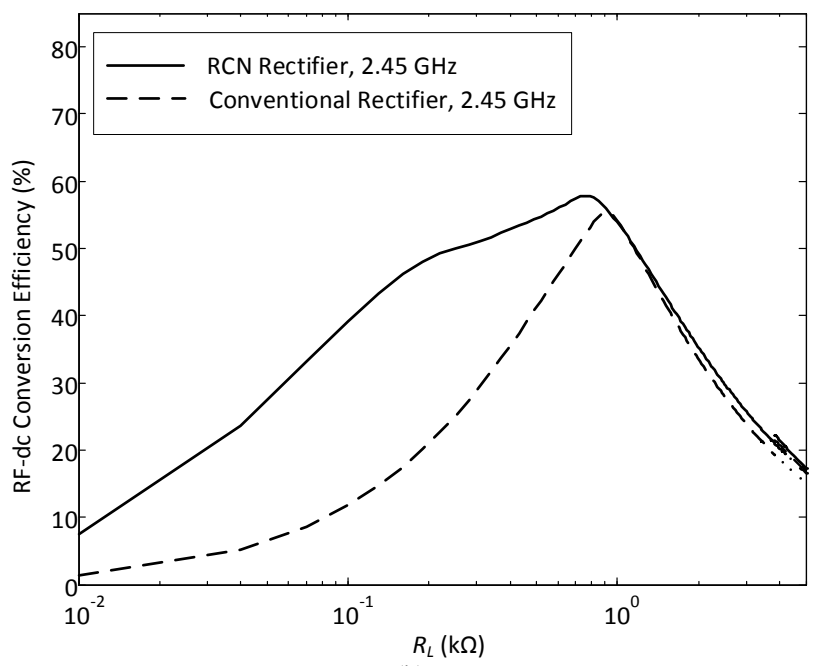

(b)

Fig. 6. Dual band RCN based rectifier [15]. RF-DC conversion efficiency versus output load compared to a conventional dual band rectifier: (a) $915 \mathrm{MHz}$, (b) $2.45 \mathrm{GHz}$. 
connected in series with some reactive elements that introduce opposite phase response in the two branches at the desired operation frequency. More recently, in [15] a dual band $\mathrm{RCN}$ based rectifier circuit has been proposed where the reactive element networks consist of dual band bandpass filters sections. These dual band bandpass sections are formed by a series and a shunt LC section. The opposite phase response in the two branches is obtained by using the same network but reversing the node where it is connected to the varying load $[14,15]$. The schematic representation of the dual band $\mathrm{RCN}$ based rectifier in [15] is shown in Fig. 5 and its RF-DC conversion efficiency is compared to the efficiency of a conventional dual band rectifier in Fig. 6, showing a higher efficiency over a wider range of load values. As it can be seen, it is possible to obtain improved performance in terms of insensitivity to load variations by sacrificing circuit complexity introducing additional circuit branches and rectifier elements.

\section{Conclusions}

In this paper a review of some of the existing challenges in WPT and EH solutions have been presented. More specifically, this paper has shown how the use of multi-band and broadband rectifiers can be used to maximize the amount of harvested power, how RCN based rectifiers can minimize the effect that load variations have on the RF-DC conversion efficiency and how the output load can be tailored to maximize the RF-DC conversion efficiency in rectenna arrays by selecting the DC power combining topology (series/parallel).

\section{References}

[1] RIZZOLI, V., BICHICCHI, G., COSTANZO, A., DONZELLI, F., MASOTTI, D. CAD of multi-resonator rectenna for micro-power generation. In 2009 European Microwave Integrated Circuits Conference (EuMIC). Rome (Italy), 2009, p. 331-334

[2] KEYROUZ, S., VISSER, H. J., TIJHUIS, A. G. Multi-band simultaneous radio frequency energy harvesting. In 7th European Conference on Antennas and Propagation (EuCAP). Gothenburg (Sweden), 2013, p. 3058-3061

[3] SCHEELER, R., KORHUMMEL, S., POPOVIC, Z. A dualfrequency ultralow-power efficient 0.5 -g rectenna. IEEE Microwave Magazine, 2014, vol. 15, no. 1, p. 109-114. DOI: 10.1109/MMM.2013.2288836

[4] OKA, T., OGATA, T., SAITO, K., TANAKA, S. Triple-band single-diode microwave rectifier using CRLH transmission line. In Proceedings of 2014 Asia-Pacific Microwave Conference. Sendai (Japan), 2014, p. 1013-1015.

[5] COLlado, A., GEORGIADIS, A. Conformal hybrid solar and electromagnetic (EM) energy harvesting rectenna. IEEE Transactions on Circuits and Systems I: Regular Papers, 2013, vol. 60 , no. 8 , p. 2225-2234. DOI: 10.1109/TCSI.2013.2239154

[6] BELO, D., GEORGIADIS, A., CARVALHO, N. B. Increasing wireless powered systems efficiency by combining WPT and electromagnetic energy harvesting. In 2016 IEEE Wireless Power
Transfer Conference (WPTC). Aveiro (Portugal), 2016, 3 p. DOI: 10.1109/WPT.2016.7498836

[7] YONG HUANG, SHINOHARA, N., TOROMURA, H. A wideband rectenna for $2.4 \mathrm{GHz}$-band RF energy harvesting. In 2016 IEEE Wireless Power Transfer Conference (WPTC). Aveiro (Portugal), 2016, 3 p. DOI: 10.1109/WPT.2016.7498816

[8] TSAI, C. H., LIAO, I.N., PAKASIRI, C., PAN, H.C., WANG, Y.J. A wideband $20 \mathrm{~mW}$ UHF rectifier in CMOS. IEEE Microwave and Wireless Components Letters, 2015, vol. 25, no. 6, p. 388-390. DOI: 10.1109/LMWC.2015.2421357

[9] ABBASIAN, S., JOHNSON, T. High efficiency GaN HEMT synchronous rectifier with an octave bandwidth for wireless power applications. In 2016 IEEE MTT-S International Microwave Symposium (IMS). San Francisco (CA, USA), 2016, 4 p. DOI: 10.1109/MWSYM.2016.7540080

[10] HAGERTY, J. A., HELMBRECHT, F. B., MCCALPIN, W. H., ZANE, R., POPOVIC, Z. B. Recycling ambient microwave energy with broad-band rectenna arrays. IEEE Transactions on Microwave Theory and Techniques, 2004, vol. 52, no. 3, p. 1014-1024. DOI: 10.1109/TMTT.2004.823585

[11] KIMIONIS, J., COLlADO, A., TENTZERIS, M. M., GEORGIADIS, A. Octave and decade UWB rectifier based on non-uniform transmission lines for energy harvesting. IEEE Transactions on Microwave Theory and Techniques, accepted for publication.

[12] MARIAN, V., VOLLAIRE, C., VERDIER, J., ALLARD, B. Potentials of an adaptive rectenna circuit. IEEE Antennas and Wireless Propagation Letters, 2011, vol. 10, p. 1393-1396. DOI: 10.1109/LAWP.2011.2178225

[13] DEL PRETE, M., COSTANZO, A., GEORGIADIS, A., COLlADO, A., MASOTTI, D., POPOVIĆ, Z. A $2.45-\mathrm{GHz}$ energy-autonomous wireless power relay node. IEEE Transactions on Microwave Theory and Techniques, 2015, vol. 63, no. 12, p. 4511-4520. DOI: 10.1109/TMTT.2015.2494003

[14] HAN, Y., LEITERMANN, O., JACKSON, D. A., RIVAS, J. M., PERREAULT, D. J. Resistance compression networks for radiofrequency power conversion. IEEE Transactions on Power Electronics, 2007, vol. 22, no. 1, p. 41-53. DOI: 10.1109/TPEL.2006.886601

[15] NIOTAKI, K., GEORGIADIS, A., COLLADO, A., VARDAKAS J. S. Dual-band resistance compression networks for improved rectifier performance. IEEE Transactions on Microwave Theory and Techniques, 2014, vol. 62, no. 12, p. 3512-3521. DOI: 10.1109/TMTT.2014.2364830

[16] GUTMANN, R. J., BORREGO, J. M. Power combining in an array of microwave power rectifiers. IEEE Transactions on Microwave Theory and Techniques, 1979, vol. 27, no. 12, p. 958-968. DOI: 10.1109/TMTT.1979.1129774

[17] SHINOHARA, N., MATSUMOTO, H. Dependence of DC output of a rectenna array on the method of interconnection of its array elements. Electrical Engineering in Japan, 1998, vol. 125, no. 1, p. 9-17. DOI: 10.1002/(SICI)1520-6416(199810)125:1<9::AID$\mathrm{EEJ} 2>3.0 . \mathrm{CO} ; 2-3$

[18] POPOVIC, Z., KORHUMMEL, S., DUNBAR, S., et al. Scalable $\mathrm{RF}$ energy harvesting. IEEE Transactions on Microwave Theory and Techniques, 2014, vol. 62, no. 4, p. 1046-1056. DOI: 10.1109/TMTT.2014.2300840

[19] BOLOS, F., BELO, D., GEORGIADIS, A. A UHF rectifier with one octave bandwidth based on a non-uniform transmission line. In 2016 IEEE MTT-S International Microwave Symposium (IMS). San Francisco (CA, USA), May 2016, 3 p. DOI: 10.1109/MWSYM.2016.7540083

[20] FANO, R. M. Theoretical Limitations on the Broadband Matching of Arbitrary Impedances. Research Laboratory of Electronics, 
Massachusetts Institute of Technology, MA, Tech. Rep. No. 41, Jan. 2, 1948

[21] BOLOS, F., BLANCO, J., COLLADO, A., GEORGIADIS, A. RF energy harvesting from multi-tone and digitally modulated signals. IEEE Transactions on Microwave Theory and Techniques, 2016, vol. 64, no. 6, p. 1918-1927. DOI: 10.1109/TMTT.2016.2561923

[22] SAKAKI, H., KUROIWA, F., TSUJI, M., et al. A novel wide dynamic range rectifier design for wireless power transfer system. In 2014 Asia-Pacific Microwave Conference. Sendai (Japan), 2014 , p. $1208-1210$

\section{About the Authors ...}

Ana COLLADO received the M.Sc. and Ph.D. degrees in Telecommunications Engineering from the University of Cantabria, Spain, in 2002 and 2007, respectively. From 2007 to 2016 she worked as a Senior Research Associate and the Project Management Coordinator at the Technological Telecommunications Center of Catalonia (CTTC), Barcelona, Spain. Since 2016 she works at Heriot-Watt University (UK) as an Assistant Professor in the Microwaves and Antennas Research Group at the School of Engineering and Physical Sciences. Her professional interests include active antennas, substrate integrated waveguide structures, nonlinear circuit design, and energy harvesting and wireless power transmission (WPT) solutions for self-sustainable and energy efficient systems. She has participated in national and international research projects and has co-authored over 90 papers in journals and conferences. Among her activities she has collaborated in the organization of several international workshops in different countries of the European Union and also a Training School for PhD students. She serves in the Editorial Board of the Radioengineering Journal and she is currently an Associate Editor of the IEEE Microwave Magazine, an Associate Editor of the IET Microwaves, Antennas and Propagation journal, a member of the Editorial Board of the Cambridge Wireless Power Transfer Journal and a member of the IEEE MTT-26 Wireless Energy Transfer and Conversion and MTT-24 RFID Technologies.

Spyridon-Nektarios DASKALAKIS was born in Heraklion, Greece, in 1991. He received his Engineering Diploma with excellence and the M.Sc. in Electronic and Computer Engineering from Technical University of Crete (TUC) in 2014 and 2016, respectively. He is currently working toward the Ph.D. degree in the School of Engineering \& Physical Science, Heriot Watt University, Edinburgh UK. His current research interests include low-cost wireless sensor networks and RF energy harvesting. Particularly he focuses on backscatter scatter communication, batteryless sensors, PCB design, low cost software defined radio, environmental sensing and RF energy harvesting. He has received fellowship award for his project Aristeos (olive fly detection and monitoring with wireless sensor network) by the Clinton Global Initiative University 2014, Phoenix Arizona USA and the Onassis Foundation graduate studies 2015/16 scholarship. $\mathrm{He}$ is co-founder of kaloudia.com platform. Finally, he was the recipient for two short term scientific mission grants form COST Action IC1301 WiPE in Electrical and Computer Engineering, Georgia Institute of Technology (2016) and in Centre Tecnològic de Telecomunicacions de Catalunya (2015).

Kyriaki NIOTAKI (S'11) was born in Crete, Greece. She received the B.S. degree in Informatics and M.S. degree in Electronic Physics (with a specialization in electronic telecommunication technology) from the Aristotle University of Thessaloniki, Thessaloniki, Greece, in 2009 and 2011, respectively, and her Ph.D. degree in 2014 at the Signal Theory and Communications Department, Technical University of Catalonia (UPC), Barcelona, Spain. From December 2011 until December 2014, she worked at the Centre Tecnologic de Telecomunicacions de Catalunya (CTTC), Barcelona, Spain, as a Research Assistant. Since June 2015 she is working for Benetel Ltd. Her main research interests include energy harvesting solutions and the design of power amplifiers. Ms. Niotaki was the recipient of an IEEE Microwave Theory and Techniques Society (IEEE MTT-S) Graduate Fellowship Award.

Ricard MARTINEZ got his B.Sc. degree in Telecommunications Engineering from the Polytechnic University of Catalonia (UPC), Catalonia, Spain in 2015. From 2014 until 2015, he was a Research Assistant with the Centre Tecnologic de Telecomunicacions de Catalunya (CTTC), Barcelona, Spain.

Ferran BOLOS was born in Barcelona, Spain, in 1990. He got his B.Sc. degree in Telecommunications Engineering at the Polytechnic University of Catalonia (UPC), Catalonia, Spain in 2015. Since 2015, he has been a Research Assistant with the Centre Tecnologic de Telecomunicacions de Catalunya (CTTC), Barcelona, Spain. His research interests include rectennas, rectifiers, wireless power transmission, and RF energy harvesting.

Apostolos GEORGIADIS was born in Thessaloniki, Greece. He received the B.S. degree in Physics and the M.S. degree in Telecommunications from the Aristotle University of Thessaloniki, Greece, in 1993 and 1996, respectively. He received the Ph.D. degree in Electrical Engineering from the University of Massachusetts, Amherst, in 2002. In 2002 he joined Global Communications Devices (GCD), North Andover MA USA, as a Systems Engineer and worked on CMOS transceivers for wireless network applications. In June 2003, he joined Bermai, Inc., Minnetonka MN USA, as an RF/Analog Systems Architect. In 2005 he joined the University of Cantabria, Spain, as a Juan de la Cierva Fellow researcher. In 2006 he was a consultant for Bitwave Semiconductor, Lowell MA, US. In addition he collaborated with ACORDE S.A., Santander, Spain, in the design of integrated CMOS VCOs for ultra-wideband (UWB) applications. In March 2007, he joined CTTC, Spain as a senior researcher in communications subsystems. In 2013-2016 he was a group leader of the Microwave Systems and Nanotechnology Department at CTTC. In July 2016, he joined 
Heriot-Watt University, Edinburgh as an Associate Professor. In 1996, Dr. Georgiadis received a Fulbright Scholarship for graduate studies at the University of Massachusetts, Amherst. He was the General Chair of 2011 IEEE RFID-TA Conference and general co-Chair of the 2011 IEEE MTT-S IMWS on Millimeter Wave Integration Technologies. He is a EU Marie Curie Global Fellow. He is a Member of the IEEE MTT-S TC-24 RFID Technologies (past Chair) and Member of IEEE MTT-S TC-26 Wireless Energy Transfer and Conversion. He was an Associate Editor of the IET Microwaves Antennas and Propagation Journals, IEEE Microwave and Wireless Components Letters and the IEEE RFID Virtual Journal. He serves as an Associate Editor of the IEEE Journal on RFID and he is the founder and Editor in Chief of the
Wireless Power Transfer journal by Cambridge University Press. He is a Vice Chair of URSI Commission D, Electronics and Photonics and ADCOM Member of IEEE Council on RFID serving as a Vice President of Conferences. He is a Distinguished Lecturer of IEEE Council on RFID. In 2016 his proposal for Inkjet/3D printed millimeter wave systems received the Bell Labs Prize, 3rd place among more than 250 proposals recognizing ideas that 'change the game' in the field of information and communications technologies. His research interests include energy harvesting and wireless power transmission, RFID technology, active antennas and phased array antennas, inkjet and 3D printed electronics, millimeter wave systems. He has published more than 160 papers in peer reviewed journals and international conferences. 